\title{
SURVEY OF PSYCHOLOGICAL DISTRESS AMONG THE UNDERGRADUATE STUDENTS OF ARTS AND SCIENCE COLLEGES IN MANGALORE, INDIA
}

\author{
Aneesh Bhat ${ }^{1}$, Praveen Jain ${ }^{2}$, Anish Cherian ${ }^{3}$, Divya Prabha D'Souza ${ }^{4}$, Shishir Kumar ${ }^{5}$, Christofer Thomas ${ }^{6}$, Chriss Thomas $^{7}$, \\ Satheesh $\mathrm{Rao}^{8}$ \\ ${ }^{1}$ Assistant Professor, Department of Psychiatry, K. S. Hegde Medical Academy, Mangalore. \\ ${ }^{2}$ Lecturer, Department of Psychiatry, K. S. Hegde Medical Academy, Mangalore. \\ ${ }^{3}$ Assistant Professor, Department of Psychiatry, K. S. Hegde Medical Academy, Mangalore. \\ ${ }^{4}$ Research Associate, Department of Psychiatry, K. S. Hegde Medical Academy, Mangalore. \\ ${ }^{5}$ Assistant Professor, Department of Psychiatry, K. S. Hegde Medical Academy, Mangalore. \\ ${ }^{6}$ Assistant Professor, Department of Physiology, Sapthagiri Institute of Medical Sciences and Research Centre, Bangalore, India. \\ ${ }^{7}$ Senior Librarian, College of Nursing, Jubilee Mission Medical College and Research Centre, Trissur, India. \\ sProfessor, Department of Psychiatry, K. S. Hegde Medical Academy, Mangalore.
}

\begin{abstract}
BACKGROUND

There is paucity of data related to the psychological and physical status of undergraduate college students in India.

\section{METHOD}

The sample consisted of 2708 undergraduate students of various arts and science colleges across the city of Mangalore, Karnataka. The study was approved by Nitte University Institutional Ethics Committee and permission was sought from the concerned colleges. Students were cross-sectionally assessed with a specially constructed semi-structured proforma and SRQ-20 (WHO), which was self-administered by the students after giving the students brief instructions. The score of 6 was taken as cut off for the SRQ screening purpose. The score of 6 and above indicates psychological morbidity and need for further detailed evaluation.
\end{abstract}

\section{RESULTS}

Of the 2708 participants who took part in the study, 64.1\% ( $n=1736)$ were females and 35.9\% ( $n=972)$ were males. The mean age of participants was $18.6 \pm 1.15$ years. $75.6 \%$ students were staying at home. Nearly $7.6 \%$ of students were using alcohol or some other form of substances. Percentage of students with SRQ scores of 6 and above was 37.9\%, which indicates that those many students were having psychological distress and needed further detailed evaluation psychiatrically. On SRQ individual item sc ore, it was found that $42.8 \%$ had regular headaches, $43.3 \%$ always felt nervous, worried, and tense, $32.2 \%$ felt tired all the time. All these are somatic symptoms of depression in students. Alarming finding was $15.6 \%$ of students felt to end their life, which indicates suicidal risk among students and indirectly points towards the unnoticed depression among them.

\section{CONCLUSION}

Our results show that the psychiatric morbidity like depression, suicidal ideation, and somatic symptoms of psychiatric illness is very high among undergraduate college students and needs to be addressed very seriously at institutional level and also at policy level by educational department and colleges.

\section{KEYWORDS}

SRQ, Undergraduate, Students, CV Depression.

HOW TO CITE THIS ARTICLE: Bhat A, Jain P, Cherian A, et al. Survey of psychological distress among the undergraduate students of arts and science colleges in Mangalore, India. J. Evolution Med. Dent. Sci. 2016;5(54):3640-3644, DOI: 10.14260/jemds/2016/839

\section{INTRODUCTION}

Undergraduate students usually come under the age group of 16-23 years. This is the adolescent to adult transition phase in life of every individual. This age is associated with numerous changes, which very actively occur in physical, psychological, social, educational, family, friends, and relationship domains. Thus, because of these constant changes in all the domains of life, individual is more stressed and also faces tremendous mental pressure from all areas of life [1].

Financial or Other, Competing Interest: None.

Submission 25-05-2016, Peer Review 19-06-2016,

Acceptance 25-06-2016, Published 07-07-2016.

Corresponding Author:

Dr. Aneesh Bhat,

Flat 005,

Landlinks Paradise 1 Apartment,

Derebail, Konchady,

Mangalore-575008, Karnataka.

E-mail: bhataneesh@gmail.com

DOI: 10.14260/jemds/2016/839
Undergraduate students are more prone to such type of psychological stress because of competitive academic curriculum, pressure to perform, etc. making it the most important source of chronic and acute stress for young people in both Western and Asian countries. It has significant association with mental health problems such as depression, anxiety, and suicidal ideation in the students of this age group.[1,2,3]. This age group is more prone to suffer from mental distress leading to onset of mental disorders like depression, anxiety, psychosis, substance use, suicide etc. This age is very crucial because most of the psychiatric disorders have their onset in this age group.[4]. Thus, among all psychiatric conditions, depression is the most common disorder with lifetime prevalence of $16.2 \%$ and 12 month prevalence of $6.6 \%$ in general population. ${ }^{[5]}$ Depressive disorder has become a common mental health problem in college students all over the world with an estimated 1 year prevalence of $4-5 \%$ in mid-tolate adolescence.[6,7] 
Depression in adolescence is one of the major risk factors for suicide and it is second-to-third leading cause of death in this age group.[6] Depression also leads to serious impairment in social and educational performance, increased substance taking behaviour, obesity, tiredness, fatigue, etc.[8] Psychiatric morbidity in this age negatively impacts their growth and development, school performance, peer or family relationships, self-respect, self-image, and may lead to suicidal thinking also. ${ }^{[9]}$ Thus, during this transition period of life, any disturbance in psychological functioning leads to negative outcome in all fields of the individual's life leading to significant disability, difficulty in studies, lack of concentration, frequent failure in exams, troubled relationships, substance use, impulsivity in decisions, physical health problems, sleep disturbances, etc.[10]. Thus, it leads to disability burden on parents and society. Psychological distress in college students mostly goes unnoticed because of variations in presentation like prominence of irritability, mood reactivity, fluctuating symptoms, increased somatic symptoms, lack of awareness, hesitance to communicate, etc.[11,12] leading to delayed diagnosis and increased disability in this age group. Different studies conducted worldwide have found higher prevalence of psychological distress among college going student population and also higher suicidal ideation in this age group making it one of the most common causes of death.[6,13]

Thus, it becomes all the more important to screen students of undergraduate courses for psychological disorders like depression, anxiety, suicidal ideation, substance use, etc. Therefore, the aim of this cross-sectional survey was to screen students for psychological distress and to find the percentage of students who really requires detailed assessment and intervention.

Though, there are many studies conducted worldwide analysing depression in student population, the data from India is sparse and not representative of complete population. So, this study was conducted in an effort to collect data and analyse it to determine the real situation in undergraduate student population in India and formulate interventional plan for this population at college, family, and social level.

\section{MATERIALS AND METHODS}

The ethical clearance for the study was obtained from institutional ethical committee of NITTE University, Deralakatte, Mangalore, Karnataka.

\section{Study Setting}

Study was conducted in $n=2708$ undergraduate students in the age group of 18-25 years studying in various arts and science colleges across the city of Mangalore, India from August 2014 to August 2015. Prior permission was taken from these colleges for conducting study among students. Informed consent was obtained for the participation in the study from the students individually.

\section{Study Design}

Cross-sectional survey.

\section{Inclusion Criteria}

1. College students aged between 18-25.

2. Willing to participate in the study and to give signed informed consent.

\section{Exclusion Criteria}

1. Severe mental or physical ailment.

2. Inability to give consent for the study.

\section{Study Tools}

1. Socio-Demographic Proforma.

2. Self-Reporting Questionnaire (SRQ, WHO)-20: SRQ-20 includes the items indicative of non-psychotic mental health disorders and physical symptoms.

\section{METHOD}

Students were given the consent form, questionnaire for sociodemographic details, and SRQ-20. Students were informed regarding the questionnaire and how to score it and how to interpret each question. Any difficulty to students in answering the questionnaire was addressed with explanation and guidance.

\section{Socio-Demographic Details}

Socio-demographic details like age, sex, residence, and an extra question of substance use etc. were collected.

\section{SRQ-20}

This is a self-administered questionnaire formulated by WHO as a screening instrument for screening of psychological and physical symptoms in general population. It consists of 20 items. Each of 20 items is scored either 0 or 1 where 0 indicates no symptoms in last one month and score 1 indicates presence of the symptoms. The maximum score is 20 . This instrument is validated and reliable as a screening instrument. In the current study, SRQ score of 6 and above were considered positive for screening and detailed assessment of psychiatric morbidity. In a study conducted in Rwandan community setting, which analysed the psychometric property and validity of SRQ-20 as screening tool, it was found that the SRQ-20 is highly reliable tool for screening of non-psychotic common mental condition in population.[14]

\section{Statistical Analysis}

SPSS version 15 was used for statistical analysis of data. Frequencies of different variables were calculated in sociodemographic data and on each question on SRQ-20. The cutoff score on SRQ was determined as 6 considering the previous studies, which used SRQ-20.

\section{RESULTS}

The results of this study have shown some very important outcomes regarding psychological status of undergraduate student population. Mean age of study population was 18.6 years with standard deviation of 1.15 years. Females were $64.1 \%$ as compared to males $35.9 \%$ among the students who participated in the study. This indicates that there is higher number of female population in the undergraduate colleges. This is a good indicator of women's education. In study population, around $75.6 \%$ students were residing at their home with parents. Only $24.4 \%$ students were staying either in hostel or in paying guest facility. $7.6 \%$ of students from study population accepted that they were using one of the substances either alcohol or others. This is a significant finding in view of early onset of substance use and significant percentage of students resorting to one of the other substances 
at the formative years of life leading to increased addiction possibilities and poor prognosis in future.

This is also a point of concern considering current scenario of substance use in India.

On detailed analysis of each component of SRQ-20, following important results were found. The somatic symptoms were very high in this study population. $42.8 \%$ of students reported of having frequent headaches, $28.7 \%$ reported that they had sleep problems, $32.2 \%$ of students mostly felt fatigued and tired all the time. Thus, these results indicate high level of somatic complaints in undergraduate students. All these complaints can be associated with undiagnosed depression in student population as found in other studies worldwide.

In this study population, $43.3 \%$ of students always felt nervous, tensed, or worried whereas $40 \%$ of them faced difficulty in taking decisions and clear thinking. This indicates higher level of anxiety and depressive symptoms among undergraduate students.

The most important part of the results is that $37.9 \%$ students, i.e. more than one third study population scored 6 or more on SRQ-20 indicating psychological distress among them and high prevalence of non-psychotic conditions among students. This warrants detailed psychiatric evaluation of every student in this study population.

Another very important result is that $15.6 \%$ of students have thoughts of ending their lives. This finding again becomes very important considering high suicidal rate among young population in India. The findings further justify the need for detailed assessment of non-psychotic psychiatric conditions among undergraduate students.

On analysis of all the above findings, it can be confirmed that there is high level of psychological distress like depression and anxiety among undergraduate students in turn leading to suicidal thoughts and hopelessness in life.

Thus, these findings indicate the need for strong psychiatric and counseling services at undergraduate level to identify and deal with psychological distress among these students and prevent morbidity and disability among them.

\begin{tabular}{|c|c|}
\hline Variables & N (\%) \\
\hline Age & $18.6(1.15)$ \\
\hline Female & $1736(64.1)$ \\
Male & $972(35.9)$ \\
\hline Residence & \\
Home & $2046(75.6)$ \\
Hostel & $393(14.5)$ \\
Paying Guest & $227(8.4)$ \\
With relatives & $42(1.5)$ \\
\hline Use of Substance/Alcohol & $207(7.6)$ \\
\hline \multicolumn{2}{|c|}{ Table 1: Basic Demographic Information }
\end{tabular}

\begin{tabular}{|l|c|}
\hline \multicolumn{1}{|c|}{ Variables } & N (\%) \\
\hline Do you often have headaches? & $\mathbf{1 1 5 9 ( 4 2 . 8 )}$ \\
\hline Is your appetite poor? & $382(14.1)$ \\
\hline Do you sleep badly? & $777(28.7)$ \\
\hline Are you easily frightened? & $718(26.5)$ \\
\hline Do your hands shake? & $647(23.1)$ \\
\hline $\begin{array}{l}\text { Do you feel Nervous, Tense, or } \\
\text { Worried? }\end{array}$ & $\mathbf{1 1 7 3 ( 4 3 . 3 )}$ \\
\hline
\end{tabular}

\begin{tabular}{|l|c|}
\hline Is your digestion poor? & $317(11.7)$ \\
\hline $\begin{array}{l}\text { Do you have trouble thinking } \\
\text { clearly? }\end{array}$ & $761(28.1)$ \\
\hline Do you feel unhappy? & $810(29.9)$ \\
\hline Do you cry more than usual? & $376(13.9)$ \\
\hline $\begin{array}{l}\text { Do you find it difficult to enjoy your } \\
\text { daily activities? }\end{array}$ & $535(19.8)$ \\
\hline $\begin{array}{l}\text { Do you find it difficult to make } \\
\text { decisions? }\end{array}$ & $\mathbf{1 0 . 8 3 ( 4 0 . 0 )}$ \\
\hline Is your daily work suffering? & $542(20.0)$ \\
\hline $\begin{array}{l}\text { Are you unable to play a useful part } \\
\text { in life? }\end{array}$ & $552(20.4)$ \\
\hline Have you lost interest in things? & $528(19.5)$ \\
\hline $\begin{array}{l}\text { Do you feel that you are a worthless } \\
\text { person? }\end{array}$ & $316(11.7)$ \\
\hline $\begin{array}{l}\text { Has the thought of ending your } \\
\text { life been on your mind? }\end{array}$ & $\mathbf{4 2 3 ( 1 5 . 6 )}$ \\
\hline Do you feel tired all the time? & $\mathbf{8 7 3 ( 3 2 . 2 )}$ \\
\hline $\begin{array}{l}\text { Do you have uncomfortable feelings } \\
\text { in your stomach? }\end{array}$ & $502(18.5)$ \\
\hline Are you easily tired? & 780 (28.8) \\
\hline Having score more 6 on SRQ & $\mathbf{1 0 2 8 ( 3 7 . 9 )}$ \\
\hline \multicolumn{1}{|c|}{ Table 2: Frequency on Self-Rating Questionnaire } \\
\hline
\end{tabular}

\section{DISCUSSION}

The findings from this study are significant and are comparable to studies conducted across the world indicating that psychological stress and morbidity faced by undergraduate students in India is similar to those in other countries.

In current study, the female student population was little more than two third of total study sample. This indicates the trend of increasing female literacy in Mangalore District of Karnataka, which is a good indicator for the female literacy program. Similarly, dropping male student number is also a matter of worry.

The average age of student population was 18.6 years. This is the age when constant changes occur in psychological, physical, hormonal, academical, and relationship domain, which is very crucial for overall development of individual. Thus, this is the most vulnerable age for onset of number of mental illnesses.[11] So, this study has targeted the correct population in interest.

The important findings from the study show that $37.9 \%$ of the students scored 6 or more on SRQ, which indicates that more than one third of students have non-psychotic psychological distress like depression or other neurotic conditions. This figure is comparable with previous studies. As per 2007 American College Health Association-National College Health Assessment, a national survey of approximately 20,500 college students on 39 campuses, it was found that $43.2 \%$ of the students reported feeling depressed at least once in past 12 months. More than 3,200 university students were diagnosed as having depression, of those $39.2 \%$ students diagnosed in the past 12 months, $24.2 \%$ currently in therapy for depression, and $35.8 \%$ were taking antidepressant medication.[15,16] Thus, our study also reports similar percentage of students suffering from the psychiatric distress, which wants detailed assessment. Another review article on a systemic review and meta-analytical study conducted in Iran 
shows prevalence of depression in university students was estimated to be 33\%.[17] indicating that Indian students are also at similar risk.

This higher percentage of higher scores on SRQ-20 indicates need for the screening services for psychiatric distress in the schools and colleges.

Similarly, in this study, another very important finding is regarding the suicidal ideation or thought of suicide in the student population. This study found that $15.6 \%$ of studied population has the thought of ending their life or thought of committing suicide. This is a significantly high percentage compared to data from other studies worldwide. A study from America mentions that $10.3 \%$ of students studied admitted to "Seriously considering attempting suicide" within the past 12 months and $1.9 \%$ actually attempted suicide during that period.[15], which is lower than the current study findings. In National Suicide Mortality Representative Survey in India, the rate of suicidal death among young age population, i.e. the age of 15 years and older was about $3 \%$ and among these $40 \%$ of male suicides and $56 \%$ of female suicides occurred between age of 15-29 years. A 15 year old in India has an approximate cumulative risk of $1 \cdot 3 \%$ of dying before 80 years of age by suicide.[18] In view of this national representative study statistics, the findings from current study become very important as around $15.6 \%$ of students thought of ending their life in our study population. Thus, the results from current study strongly recommend the periodic screening and counseling services for the undergraduate students and training to their teacher to identify the risk factors for suicide.

This study also looks into the important physical and psychological symptoms, which may become useful to identify the depression among the undergraduate students. In this study, $42.8 \%$ of students complained of headache, $43.3 \%$ complained of nervousness, worries, tension, $28.1 \%$ had troubled thinking, $40 \%$ had difficulty in making decisions, $28.7 \%$ had difficulty in sleeping, whereas $32.2 \%$ of students always felt tired and less energetic. All these psychological and somatic symptoms are also associated with major depression in adolescent and young adults. A study among college students with symptoms of fatigue reports that the students with moderate-to-severe fatigue have significantly greater depressive symptom severity compared with those with mild or no fatigue and scored higher on a suicide risk measure than those with mild fatigue. Students with severe fatigue evidenced greater frequency and intensity of anxiety than those with mild or no fatigue. Cognitive and functional impairment increased significantly as fatigue worsened.[19]

Thus, the relationship between fatigue and depression is complex. Fatigue is a common symptom of depression. Often, it is a prodromal symptom of depression especially occurring with first onset of depression and also remains as a common residual depressive symptom.[19]. Fatigue or lack of energy among college students may be related to many factors like heavy course, competition, performance pressure, extracurricular activities, work obligation, social activities, drug use, etc. because of which it becomes all the more important to screen students for depression. Similarly, difficulty in sleep is also related to depression. In current study, nearly one third of students had difficulty in sleep. The study on sleep quality and psychological correlates indicates that perceived stress level and symptoms of depression and anxiety were strongly associated with sleep quality.[20]
In this study, the students also scored higher on somatic symptoms, physical symptoms of anxiety and depression, cognitive symptoms, etc. This is again in accordance with other results of this study and also the findings from different studies. In a study on college students with depressive symptoms with sleep disturbance, it was found that students experienced a greater burden of co-morbid anxiety symptoms and hyperarousal, which may lead to impairments in functioning.[10]

Thus, above results are representative of earlier studies conducted worldwide among college and university students for their psychological status. This study indicates that the Indian students experience morbidity because of psychological distress similar to the students from other places in the world.

This study results strongly recommend the need for screening and interventional strategies to prevent psychological morbidity and suicide among undergraduate students in India.

A study conducted for 2 years with various groups of interventional programs showed fivefold decrease in depression in the interventional group. ${ }^{[21]}$ representing the importance of early screening and preventive strategies.

Thus, through this study, we suggest that there is need to conduct more detailed nationally representative multi-centric study to understand actual prevalence of psychiatric morbidity and risk among undergraduate students.

\section{CONCLUSION}

There are many worldwide studies in depression and psychiatric morbidity among undergraduate student population, but this study validates the scenario in Indian students. This study has shown significant psychological distress and suicidal thoughts in this population. This result confirms the need for systematic screening program for psychiatric disturbances among this age group at college level. It also puts forward the need for awareness among students regarding the psychiatric illnesses and their symptom identifiers. More organized efforts should be done for educating students regarding their psychological needs and improving their coping skills and life skills to face the stress and strain of life. Some of the methods include early screening, preventive measures, one to one and group counseling, life skill and coping skill training, students' helpline in colleges, peer support groups, structured study methods, integration of parents in educational classes, training of teachers to identify the precursor symptoms of psychiatric disturbances. These methods may solve the problems to certain extent.

Thus, through this study, we propose the above-mentioned approaches to prevent the psychiatric morbidity in the students. We also propose to conduct the national level multicentric study to identify the trends in the student population and formulate national level strategy for prevention of the psychiatric morbidity among undergraduate students.

\section{LIMITATIONS}

The main limitation of this study is that it is conducted in the urban population, so it doesn't give clear idea of prevalence of psychological distress in rural student population. The second limitation being the exact diagnosis of psychiatric illness is not achieved in this study, so it only represents the psychological distress. Further detailed enquiry is needed for diagnosis of psychiatric condition by expert. 


\section{ACKNOWLEDGEMENTS}

1. Author acknowledges the support given by NITTE University and Department of Psychiatry K. S. Hegde Hospital, Deralakatte, Mangalore, Karnataka.

2. Authors have not received any financial support from anyone for conducting this study.

\section{REFERENCES}

1. Anderman EM. School effects on psychological outcomes during adolescence. J Edu Psycho 2002;94(4):795-809.

2. Ang RP, Huan VS. Relationship between academic stress and suicidal ideation: testing for depression as a mediator using multiple regressions. J Child Psychi Human Develop 2006;37(2):133-43.

3. Jayanthi P, Thirunavukarasu M, Rajkumar R. Academic stress and depression among adolescents: a crosssectional study. Indian Paediatrics 2015;52:217-9.

4. Kovess-Masfety V, Leray E, Denis L, et al. Mental health of college students and their non-college-attending peers: results from a large French cross-sectional survey. BMC Psychology 2016;4:20. DOI 10.1186/s40359-0160124-5.

5. Kessler RC, Berglund P, Demler O, et al. The epidemiology of major depressive disorder: results from the national comorbidity survey replication (NCS-R). JAMA 2003;289(23):3095-3105.

6. Thapar A, Collishaw S, Pine DS, et al. Depression in adolescence. Lancet 2012;379(9820):1056-67. doi:10.1016/S0140 6736(11)60871-4.

7. Lopez A, Mathers C, Ezzati M, et al. Global burden of disease and risk factors. Washington: Oxford University Press and the World Bank 2006.

8. Keenan-Miller D, Hammen CL, Brennan PA. Health outcomes related to early adolescent depression. J Adolesc Health 2007;41(3):256-62.

9. Bhatia SK, Bhatia SC. Childhood and adolescent depression. Am Fam Physician 2007;75(1):73-80.

10. Nyer M, Farabaugh A, Fehling K, et al. Relationship between sleep disturbance and depression ,anxiety, and functioning in college students. Depress Anxiety 2013;30(9):873-80. doi:10.1002/da.22064.

11. Sajjadi H, Kamal SHM, Rafiey H, et al. A systematic review of the prevalence and risk factors of depression among Iranian adolescent. Global Journal of Health Science 2013;5(3):16-27.
12. Leaf PJ, Alegria M, Cohen P, et al. Mental health service use in the community and schools: results from the fourcommunity MECA study methods for the epidemiology of child and adolescent mental disorders study. J Am Acad Child Adolesc Psychiatry 196;35(7):889-97.

http://dx.doi.org/10.1097/00004583-19960700000014.

13. Windfuhr K, While D, Hunt I, et al. Suicide in juveniles and adolescents in the United Kingdom. J Child Psychol Psychiatry 2008;49(11):1155-65.

14. Scholte WF, Verduin F, Lammeren AV, et al. Psychometric properties and longitudinal validation of the selfreporting questionnaire (SRQ-20) in a Rwandan community setting: a validation study. BMC Medical Research Methodology 2011;11:116. http://www.biomedcentral.com/1471-2288/11/116.

15. Miller EJ, Chung H. A literature review of studies of depression and treatment outcomes among U.S. college students since 1990. Psychiatric Services 2009;60(9):1257-60.

16. American college health association-national college health assessment: reference group report, Fall 2007. Baltimore, American college health association, 2008. www.acha-ncha.org/reports_ACHA-NCHAoriginal.html.

17. Sarokhani D, Delpisheh A, Veisani Y, et al. Prevalence of depression among university students: a systematic review and meta-analysis study. Depression Research and Treatment, Article ID 3738572013, 2013;(2013):7. http://dx.doi.org/10.1155/2013/373857.

18. Patel V, Ramasundarahettige C, Vijayakumar L, et al. Suicide mortality in India: a nationally representative survey. Lancet 2012;379(9834):2343-51. doi: 10.1016/S0140-6736(12)60606-0.

19. Nyer M, Mischoulon D, Alpert JE, et al. College students with depressive symptoms with and without fatigue: Differences in functioning, suicidality, anxiety, and depressive severity. Ann Clin Psychiatry 2015;27(2): 100-8.

20. Lemma S, Gelaye B, Berhane Y, et al. Sleep quality and its psychological correlates among university students in Ethiopia: a cross-sectional study. BMC Psychiatry 2012;12:237.

http://www.biomedcentral.com/1471-244X/12/237.

21. Rohde P, Stice E, Gau JM. Effects of three depression prevention interventions on risk for depressive disorder onset in the context of depression risk factors. Prev Scix 2012;13(6):584-93. doi: 10.1007/s11121-012-0284-3. 